\title{
Internet addiction, fatigue, and sleep problems among adolescent students: A large scale study
}

\author{
Abdulbari Bener ${ }^{* 1,2,3}$, Erol Yildirim ${ }^{4}$, Perihan Torun ${ }^{5}$, Funda Çatan ${ }^{1,6}$, \\ Erkut Bolat ${ }^{1}$, Sümmani Alıç ${ }^{1}$, Salih Akyel ${ }^{1}$, Mark D. Griffiths ${ }^{7}$ \\ ${ }^{1}$ Dept. of Biostatistics \& Medical Informatics, Cerrahpaşa Faculty of Medicine \\ Istanbul University, Istanbul, Turkey \\ ${ }^{2}$ Dept. of Evidence for Population Health Unit, School Of Epidemiology and Health Sciences, University \\ of Manchester, Manchester, UK \\ 3 Istanbul Medipol University, International School of Medicine, Kavacik, İstanbul, Turkey \\ 4 Dept. of Psychology, İstanbul Medipol University, Kavacik, 34810 Kavacık, İstanbul, Turkey \\ ${ }^{5}$ Bezmiâlem Foundation University, Faculty of Medicine, Dept. of Public Health, İstanbul, Turkey \\ ${ }^{6}$ Dept. of Computer Education and Instructional Technologies, Faculty of Education, University of \\ Kastamonu, Kastamonu, Turkey \\ ${ }^{7}$ Dept. of Psychology, School of Social Sciences, Nottingham Trent University, Nottingham, UK
}

Running Head: Internet addiction, sleep disorders, fatigue.

Key Words: Excessive internet use, sleep disorders, fatigue, Internet addiction.

\section{Correspondence to:}

Prof. Abdulbari Bener

Advisor to WHO

Professor of Public Health

Dept. of Biostatistics \& Medical Informatics

Cerrahpaşa Faculty of Medicine

Istanbul University and Istanbul Medipol University,

International School of Medicine

34098 Cerrahpasa-Istanbul, TURKEY

Mobile: +90-535 6639090

Tel: $+90-212-4143041$

Fax: + 90-212-632 0033

e-mail: abdulbari.bener@istanbul.edu.tr

email: abener99@yahoo.com 


\section{ABSTRACT}

Aim: The aim of the present study was to examine the association between Internet Addiction (IA), fatigue, and sleep problems among university students.

Methods: A total of 3,000 Turkish students aged 18 to 25 years were approached and 2,350 students (78.3\%) participated in this cross-sectional study from April 2017 to September 2017 in public and private universities in Istanbul. Data were collected via a structured questionnaire including socio-demographic details, lifestyle and dietary habits, Internet Addiction Test (IAT), Fatigue Scale, and Epworth Sleepiness Scale [ESS]. Descriptive statistics, multivariate and factorial analyses were performed.

Results: The overall prevalence of IA among the studied population was $17.7 \%$. There were significant differences between gender, family income, father's occupation, school performance, frequency and duration of watching television, physical activity, internet use duration, and sleep duration (all $p<0.001$ ). Significant differences were also found between participants with IA and those without IA in having headaches, blurred vision, double vision, hurting eyes, hearing problems, and eating fast food frequently (all $p<0.001$ ). Using multivariate regression analysis, the duration of internet use, physical and mental symptoms, headache, hurting eyes, tired eyes, hearing problems and ESS scores were significantly associated with (and primary predictors of) IA.

Conclusion: The present study demonstrated that IA was associated with poor dietary habits, sleep problems, and fatigue symptoms.

\section{INTRODUCTION}

Access to the internet via smartphones, tablets, and laptop computers have made it possible for anyone to enjoy many work and leisure activities regardless of time and physical location. Internet misuse among children and adolescents has become a widespread major public health concern worldwide [Kuss et al. 2014; Bener an Bhugra 2013]. The phenomenon of internet addiction was first described in a number of papers in the mid- to late-1990s by Griffiths and Young [Griffiths 1996; Griffiths 1998; Young 1996]. The topic immediately gained more attention and has become a highly researched area. Specific types of internet use, such as online socializing, gaming, gambling and sex, can lead to pathological behaviour [Griffiths 1998; Young and Rogers 1998, Müller et al. 2015, Kim et al. 2016]. One type of problematic 
Internet use is Internet Gaming Disorder (IGD) and has been included in the fifth edition of the Diagnostic and Statistical Manual of Mental Disorders (DSM-5) as an emerging area that requires further evidence before being included in the main text [American Psychiatric Association, 2013].

Several studies have established that in particular children and adolescents have problems and/or are becoming addicted to playing online games, in much the same way as adults become addicted to alcohol or drug or gambling [Griffiths 1998; Young 1996, Ko et al. 2010]. Several studies have demonstrated that individuals can become get addicted to online activities, particularly those that have psychological and emotional problems such as depression, anxiety, loneliness, distraction and lack of sleep [Griffiths 1998; Bener and Bhugra 2013, Demirci et al. 2015, Rehbein et al. 2015, Lam, 2014]. Moreover, excessive and/or problematic internet use can lead to physical health issues such as dry eyes, carpal tunnel syndrome, repetitive motion injuries, wrist, neck, back and shoulder pain, migraine headaches, and numbness and pain in the thumb, index and middle fingers [Park et al. 2013].

Several studies have documented adverse effects of IA among adolescents such as irregular dietary habits [Bener et al. 2010; Bener et al. 2011], physical inactivity, lack of adequate sleep [Choi et al. 2009, Canan et al. 2013, Ekinci et al. 2014], increased depression, loneliness and social anxiety [Caplan 2007; Celik et al. 2013]. These detrimental social and health effects are still being debated within the psychological, psychiatric and medical communities. The primary aim of the present study was to examine the association between Internet Addiction (IA), fatigue and sleep problems among university students.

\section{METHODS}

Participants and procedure: The present cross-sectional study comprised students aged 18 to 25 years, studying in five Istanbul Government and Trust universities (Turkey). Ethical clearance for the study was given by the Istanbul Medipol University, International School of Medicine. A multi-stage stratified random sampling technique was used and university students were selected randomly. Urban and semi-urban areas were proportionally represented by stratification. Data were collected during the period April 2017 to September 2017. The questionnaires were handed out the students at five different universities. Although 3,000 students were approached, 2,350 students participated in the study (response rate of 
78.3\%). Istanbul is a cosmopolitan city, so the sample represents all parts of Turkey. Furthermore, the value of Kaiser-Meyer-Olkin measure of sampling adequacy was found $0.91>0.6$, so the sample size was deemed good enough for all the statistical tests carried out. Content validity, face validity, and reliability of the questionnaire were tested among 148 participants. A high level of validity and high degree of repeatability was found (kappa=0.85>0.8).

Measures: The questionnaire comprised five sections. The first section included sociodemographic details of the students; the second section concerned lifestyle habits, extra physical activities and several disorders; the third section comprised the Fatigue Scale; the fourth section comprised the Epworth Sleep Scale; the final section concerned internet use and included Young's Internet Addiction Test [Young 2004].

We used the Turkish translation of Young's Internet Addiction Test (IAT) developed by Cakir and Horzum (2008). IAT comprises 20 questions to determine the level of addiction as mildly, moderately, or severely. It is evaluated on a scale up to 100: up to 49 is categorized as normal, $50-79$ is categorized as problematic, and $80-100$ is categorized as significantly problematic. Items were rated on a 6 -point scale where $0=$ does not apply, $1=$ rarely, and $5=a l w a y s$. The internal consistency (Cronbach's alpha) for the 20 items, using the responses of all participants was 0.89 . On the other hand, people were considered as internet addicted if they use internet more than 35 hours/week in Aslan's study [2010].. For the purposes of this study, students were regarded as having internet addiction if they fulfilled all of the following two inclusion criteria: an IAT score $>65$ and internet viewing of $\geq 5$ hours/day.

The Fatigue Scale comprises 14 items that determine widely seen physical and mental fatigue symptoms [Chalder et al. 1993]. The 4-point Likert scale was applied where $1=$ better than usual, $2=$ no more than usual, $3=$ worse than usual, and $4=$ much worse than usual. Cronbach's alpha for physical fatigue items (1-8) was 0.85 ; and for mental fatigue items (9-14) was 0.82 . The Epworth Sleepiness Scale [ESS] is used to assess average daytime sleepiness [Johns 2000]. The validated ESS comprises 8 items scored on a 24-point scale. Scores ranging from between 1 and 10 are normal and scores between 11 and 24 are considered to be abnormal. Epworth score varies in the range of 0-24: $<10$ denotes normal; 10-15 moderate impairment, and 16-24 severe impairment [Johns 2000]. Cronbach's alpha for the ESS was 0.88 in the present study. 
Data analysis: Factor analysis was used for data reduction purposes. It is a statistical method to reduce numerous variables into lower numbers of factors, which are more understandable [Thompson 2004]. Confirmatory factor analysis was used to determine the factor structure of the IAT. Student-t tests were performed to test the significance of differences between mean values of two continuous variables while the Mann-Whitney test was used for non-parametric data. Chi-square and Fisher's exact tests (two-tailed) were used to establish for differences in proportions of categorical variables between two or more groups. Multiple regression analysis was performed with stepwise selection, because of having detailed steps, to estimate IA score on several predictor variables in the dataset. Statistical significance was accepted at the $p<0.05$ level.

\section{RESULTS}

Factor analysis was applied on participants' responses in order to determine the psychometric features of the Internet Addiction Test (IAT). Confirmatory factor analysis (CFA) was performed on the dataset $(\mathrm{N}=2,350)$. Table 1 indicates the socio-demographic characteristics of the sample participants. Of these, $43.1 \%$ were males and $56.9 \%$ were females. The overall prevalence of IA among participants was $17.7 \%$. The proportion of IA was significantly higher among males $(54.2 \%)$ compared to females $(45.8 \% ; p<0.001)$. There were significant differences between gender, family income, father occupation, school performance, frequency and duration of watching television, and physical activity $(p<0.001)$. Those with IA had significantly less hours sleep $(6.06 \pm 1.10$ vs. $6.84 \pm 1.35 ; p<0.001)$ compared to those without IA. Those with IA had significantly high number of hours' internet use $(4.45 \pm 1.65$ vs. $3.86 \pm 1.73 ; p<0.001)$ as compared to those without IA.

Table 2 denotes confirmatory factor analysis of IAT. The variables comprised four factors that had an eigenvalue greater than 1. Factor 1 related to nine variables (Q10, Q11, Q12, Q13, Q15, Q17, Q18, Q19, Q20) and concern behavioural attitudes with and without internet. The variance for Factor 1 was 19.52. Factor 2 comprised seven variables (Q3, Q4, Q5, Q6, Q7, Q8, Q9). These concern the effects of being online. The variance for Factor 2 was 16.49. Factor 3 comprised two variables (Q14, Q16) and concern controlling time when online. Factor 4 comprised two variables (Q1, Q2) and concerned the spending of more time online. In Figure 1, as a result of reliability analysis, Cronbach's alpha of the scale was satisfactory (Factor $1=18.76$, Factor $2=13.65$, Factor $3=12.18$, Factor $4=10.56$ ). Figure was drawn by using AMOS, and all standardized values have to be smaller than 1. The CFA 
provided the following results: $X^{2}=11.53(p<0.001)$, root mean square error of approximation $($ RMSEA $)=0.06$ with the criteria of $<0.08$ [Stevens 2001], goodness of fit index $(G F I)=0.92$ $(\geq 0.9)$ [Hair et al. 2010], comparative fit index (CFI) $=0.88(\geq 0.9)$ [Hair, et al. 2010], adjusted goodness of fit index $(\mathrm{AGFI})=0.91 \quad(\geq 0.9)$, standardized root mean square residual $(S R M R)=0.07 \quad(\leq 0.05) \quad$ [Schermelleh-Engel and Moosbrugger 2003], normed fit index $(\mathrm{NFI})=0.88(\geq 0.9)$ and non-normed fit index $(\mathrm{NNFI})=0.87(\geq 0.9)$ [Schermelleh-Engel and Moosbrugger 2003].

Table 3 shows the lifestyle habits, diet, and co-morbid factors comparing internet addicted participants with those not addicted. Significant differences were found between IA and non-IA participants in having headaches, blurred vision, double vision, hurting eyes, hearing problems, and eating fast food frequently (all $p<0.001$ ). Significantly fewer participants with IA reported having vigorous and moderate activities compared to non-IA participants $(p<0.01)$. Table 4 presents compares fatigue disorders of those with IA to non-IA participants. Those with IA had significantly higher fatigue disorder scores, especially physical fatigue, due to the significantly high number of hours' internet use $(p<0.001)$ as compared to non-IA participants. Table 5 shows the multiple linear regression analysis to determine the potential predictors as risk factors for internet addiction. This analysis demonstrated that the duration of internet use, physical fatigue, mental symptoms, sleepiness (as assessed using the EES), headaches, hurting eyes, tired eyes, and hearing problems were significantly associated with (and key predictors of) internet addiction.

\section{DISCUSSION}

The present study clearly demonstrated that IA was related to a wide range of comorbid factors and poor lifestyle habits. The prevalence of IA in the present Turkish sample $(17.7 \%)$ is higher than that of China (11\%) [Lam et al. 2009], Australia (10.8\%) [Choi et al. 2009], Greece (8\%) [Siomos et al. 2009], Taiwan (17.1\%) [Liu et al. 2017] and the USA (9\%) [Caplan 2007]. Moreover, IA affects approximately $1.2 \%$ to $26.3 \%$ of U.S. university students [Li et al. 2015]. Although it is difficult to compare the exact prevalence of IA due to the lack of a shared criteria and assessment instrument used, the present study highlights the importance of using a robust psychometrically validated scale. The present study examined the psychometric features of the IA test using factorial. 
Researchers have used different terms to describe adverse impacts of excessive internet use on individuals, including (but not limited to) internet addiction, internet addiction disorder, internet use disorder, internet dependence, problematic internet use, and pathological internet use [Kusss et al. 2014; Griffiths 1998; Choi et al. 2009]. A recent crosssectional study of 1,156 students in the Mersin Province of Turkey reported that 175 students (15.1\%) were considered as Internet addicts [Sasmaz et al. 2014]. The prevalence rate of internet addiction was $9.3 \%$ in girls and $20.4 \%$ in boys $(p<0.001)$, and is therefore in line with findings from the present study. Several studies in Turkey was examined the relationship between internet addiction and depression [Gunay at al. 2018] and anxiety [Seyrek et al 2017], internet and sleep problems [Canan et al. 2013; Ekinci et al. 2014; Bhandari et al. 2017], internet and loneliness [Celik et al. 2014]. Yilmazsoy and Kahraman [2017] found that the level of internet addiction is related to the duration of internet usage and the increased duration of internet usage leads to increase in the level of internet addiction. This is confirmatory with present research. Moreover, this is the first study to investigate the relationship between internet addiction, fatigue and sleeping problems among young Turkish population.

Nevertheless, a large body of literature suggests that internet addiction has negative effects on individuals' abilities [Kusss et al. 2014; Griffiths 1996; Griffiths 1998; Choi et al. 2009, Bener and Bhugra 2013, Niemz et al. 2005], irregular dietary habits [Bener et al. 2010; Bener et al 2011; Park et al. 2013], physical inactivity [Bener et al. 2010; Bener et al. 2011; Kusss et al. 2014; Griffiths 1996; Griffiths 1998] and adequate sleep [Canan et al. 2013; Ekinci et al. 2014; Bhandari et al. 2017]. Furthermore, a Korean study reported a significant association between IA, sleep disturbances, fatigue symptoms, and fast food consumption [Kim et al. 2010]. The results of the present study concur with these findings. Previous research has also established that computer screen lights can have negative effect on circadian rhythm and lead to sleep phase delay [Petit et al. 2016]. Similarly, IA plays an important role in daytime sleepiness and sleeping disorders [Ferreira et al. 2017] and fatigue [Lin et al. 2013]. Other study has also reported that IA has negative impacts on sleep including sleep deprivation and fatigue [Bener et al. 2016].

The present study is not without its limitations. Firstly, common diagnostic criteria for IA differ across studies and the present study used the most widely used measure but arguably the most out-of-date. Secondly, there may be reporting bias by students such as hiding the duration of internet use due to the self-reported scale (along with other well-known biases 
common to all self-report methods such as memory recall). Finally, family factors related to IA were not evaluated as potential variables in the present study. Despite these limitations, the present study demonstrated that IA was associated with poor dietary habits, sleep problems, and fatigue symptoms using a relatively largescale sample. Using confirmatory factor analysis, the study investigated the latent structure of the IAT scale and results support its reliability and validity.

\section{Acknowledgment:}

This work was supported by the Istanbul Medipol University, International School of Medicine. The authors would like to thank the Istanbul Medipol University for their support and ethical approval (Research Protool and IRB\# 10840098-604.01.01-E.9713).

Informed Consent: Verbal informed consent was obtained for this study due to its nature.

Authors' contributions: $A B$, and EY organized study, collected data, performed statistical analysis and wrote the first draft of the article, and contributed to the interpretation of the data and writing the final draft of manuscript. PT, FÇ, EB, and SA collected data, performed statistical analysis and wrote the first draft of the article. MDG contributed to the interpretation of the data and writing the manuscript.

Conflict of Interest: No conflict of interest was declared by the authors.

Financial Disclosure: The authors declared that this study has received no financial support.

\section{REFERENCES}

American Psychiatric Association. (2013).Diagnostic and statistical manual of mental disorders (5th ed.). Arlington: American Psychiatric Association.

Bener A, Al-Mahdi HS, Ali Al, Al-Nufal M, Vachhani PJ, Tewfik I. Obesity and low vision as a result of excessive internet use and television viewing. International Journal of Food Science and Nutrition 2011. 62(1): 60-62.

Bener A, Al-Mahdi HS, Bhugra D. Lifestyle Factors and Internet Addiction among School Children. International Journal of Community Family Medicine. 2016, 1: 118.

Bener A, Al-Mahdi HS, Vachhani PJ, Al-Nufal M, Ali Al. Do excessive internet use, television viewing and poor life-style habits affect low vision in school children? Journal Child Health Care 2010; 14:375-385.

Bener A, Bhugra D. Lifestyle and depressive risk factors associated with problematic internet use in adolescents in an Arabian Gulf culture. Journal of Addiction Medicine, 2013; 7: 236-242. 
Bhandari PM, Neupane D, Rijal S, Thapa K, Mishra SR, and Poudyal AM. Sleep quality, internet addiction and depressive symptoms among undergraduate students in Nepal. BMC Psychiatry 2017, 17:106.

Hair, J.F., Black, W.C., Babin, B.J., Anderson, R.E. Multivariate Data Analysis. Seventh Edition. Prentice Hall, Upper Saddle River, New Jersey, 2010.

Canan, F, Yildirim, O, Sinani, G, Ozturk, O, Ustunel, TY, Ataoglu, A. Internet addiction and sleep disturbance symptoms among Turkish high school students. Sleep and Biological Rhythms, 2013; 11(3), 210-213.

Caplan SE. Relations among loneliness, social anxiety, and problematic Internet use. Cyberpsycho Behavior 2007; 10(2):234-42

Celik, V, Yesilyurt E, Korkmaz O, Usta E. From the Perspective of Loneliness and Cognitive Absorption Internet Addiction as Predictor and Predicted. Eurasia Journal of Mathematics, Science \& Technology Education. 2014: 10(6).

Chalder T, Berelowitz G, Pawlikowska T, Watts L, Wessely S, Wright D, Wallace EP. Development of a fatigue scale. Journal Psychosomatic Research. 1993; 37(2):147-53.

Choi K, Son H, Park M, Han J, Kim K, Lee B, Gwak H. Internet overuse and excessive daytime sleepiness in adolescents. Psychiatry and Clinical Neurosciences 2009; 63:455-62.

Cakır Balta O, Horzum MB. Internet Addiction Test. Journal of Educational Sciences \& Practice. 2008; 7(13):99-121.

Demirci, K., Akgönül, M., Akpinar, A. (2015). Relationship of smartphone use severity with sleep quality, depression, and anxiety in university students. Journal of Behavioral Addictions. 2015; 4(2), 85-92.

Ekinci, Ö, Celik, T., SAVAŞ, N., \& Toros, F. Association between internet use and sleep problems in adolescents. Nöro Psikiyatri Arşivi, 2014; 51(2), 122.

Ferreira C, Ferreira H, Vieira MJ, Costeira M, Branco L, Dias A, Macedo L. Epidemiology of Internet Use by an Adolescent Population and its Relation with Sleep Habits. Acta Medica Portuguesa journal 2017, 30(7-8):524-533.

Griffiths, MD. Internet addiction: An issue for clinical psychology? Clinical Psychology Forum 1996; 97:32-36.

Griffiths, MD. Internet addiction: does it really exist? In J. Gackenbach (Ed.), Psychology and the Internet: Intrapersonal, interpersonal, and transpersonal implications. San Diego, CA: Academic Press, 61-75; 1998.

Gunay O, Ozturk A, Arslantas EE, Sevinc N. Internet Addiction and Depression Levels in Erciyes University Students. Journal of Psychiatry \& Neurological Sciences. 2018;1;31(1). 
Johns MW. Sensitivity and specificity of the multiple sleep latency test (MSLT), the maintenance of the wakefulness test and the Epworth Sleepiness Scale: Failure of the MSLT as a gold standard. Journal Sleep Research 2000; 9:5-11.

Kim, N. R., Hwang, S. S.-H., Choi, J.-S., Kim, D.-J., Demetrovics, Z., Király, O., Nagygyörgy, K., Griffiths, M. D., Hyun, S. Y., Youn, H. C., \&. Youn, H. C. Characteristics and psychiatric symptoms of Internet gaming disorder among adults using self-reported DSM-5 criteria. Psychiatry Investigation. 2016; 13(1), 58-66.

Kim Y, Park JY, Kim SB, Jung IK, Lim YS, Kim JH. The effects of Internet addiction on the lifestyle and dietary behavior of Korean adolescents. Nutrition Research Practice 2010; 4(1):51-57.

Ko CH, Yen JY, Yen CF, Chen CS, Weng CC, Chen CC. The association between Internet addiction and problematic alcohol use in adolescents: the problem behavior model. CyberPsychology \& Behavior. 2008;11(5):571-6.

Kuss DJ, Griffiths MD, Karila L, Billieux J. Internet addiction: A systematic review of epidemiological research for the last decade. Current Pharmaceutical Design 2014; 20:4026-4052.

Lam LT, Peng ZW, Mai JC, Jing J. Factors associated with Internet addiction among adolescents. Cyberpsychol Behavior 2009; 12:1-5.

Lam, LT. Internet gaming addiction, problematic use of the Internet, and sleep problems: A systematic review. Current Psychiatry Reports. 2014; 16(4), 444.

Li W, O'Brien JE, Snyder SM, Howard MO. Characteristics of internet addiction/pathological internet use in U.S. university students: A qualitative-method investigation. PLoS ONE. 2015 3;10(2):e0117372

Lin SC, Tsai KW, Chen MW, Koo M. Association between fatigue and Internet addiction in female hospital nurses. Journal Advanced Nursing 2013;69(2):374-83.

Liu HC, Liu SI, Tjung JJ, Sun FJ, Huang HC, Fang CK. Self-harm and its association with internet addiction and internet exposure to suicidal thought in adolescents. Journal of the Formosan Medical Association. 2017;116(3):153-160.

Müller, K., Janikian, M., Dreier, M., Wölfling, K., Beutel, M., Tzavara, C., Richardson, C., \& Tsitsika, A. Regular gaming behavior and Internet gaming disorder in European adolescents: Results from a cross-national representative survey of prevalence, predictors, and psychopathological correlates. European Child \& Adolescent Psychiatry. 2015; 24(5), 565-574.

Niemz K, Griffiths MD, Banyard P. Prevalence of pathological Internet use among university students and correlations with self-esteem, the general health questionnaire (GHQ), and disinhibition. CyberPsychology Behavior, 2005; 8: 562-570. 
Park S, Hong KE, Park EJ, Ha KS, Yoo HJ. The association between problematic internet use and depression, suicidal ideation and bipolar disorder symptoms in Korean adolescents. Australian \& New Zealand Journal of Psychiatry 2013; 47: 153-9.

Petit A, Karila L, Estellat C, Moisan D, Reynaud M, D'Ortho MP, Lejoyeux M, Levy F, Sleep disorders in Internet addiction. Presse Medicale journal 2016, 1170-1177.

Rehbein, F., Kliem, S., Baier, D., Mößle, T., Petry, NM. Prevalence of Internet gaming disorder in German adolescents: Diagnostic contribution of the nine DSM- 5 criteria in a state- wide representative sample. Addiction. 2015; 110(5), 842-851.

Schermelleh-Engel, K., Moosbrugger, H. Evaluating the fit of structural equation models: tests of significance and descriptive goodness-of-fit measures. Methods of Psychological Research Online. 2003; 8(2), 23-74.

Seyrek, S, Cop, E, Sinir, H, Ugurlu, M, \& Şenel, S. Factors associated with Internet addiction: Cross- sectional study of Turkish adolescents. Pediatrics International, 2017; 59(2), 218-222.

Siomos KE, Dafouli ED, Braimiotis DA, Mouzas OD, Angelopoulos NV. Internet addiction among Greek adolescent students. Cyberpsychol Behavior 2008; 11:653-657.

Stevens, J.P. Applied Multivariate Statistics for the Social Sciences, Taylor\&Francis, 2001.

Şaşmaz T, Öner S, Kurt AÖ, Yapıcı G, Buğdaycı R, Şiş M. Prevalence and risk factors of Internet addiction in high school students. European Journal of Public Health, 2014; 24: 15-20.

Thompson B. Exploratory and Confirmatory Factor Analysis: Understanding Concepts and Applications Third Edition, Hardcover:195 pages; Publisher: American Psychiatric Association; 2004.

Aslan A, Yazici A. Internet Addiction Among University Students and Related Sociodemografic Factors. Turkish Journal of Clinical Psychiatry; 2016: 19-3:109-117.

Yilmazsoy B, Kahraman M. Determining of the level of internet addiction of distance learning students. Journal of Open Education Practices and Research. 2017;3(4):9-29.

Young K. Psychology of computer use: XL. Addictive use of the Internet: A case that breaks the stereotype. Psychological Reports 1996; 79:899-902.

Young KS, Rogers RC. The relationship between depression and Internet addiction. CyberPsychology and Behavior 1998; 1(1):25-28.

Young, KS. Internet addiction - A new clinical phenomenon and its consequences. American Behavioral Scientist, 2004; 48(4): 402-415. 
Table 1. Socio-demographics Characteristics of the Studied Students $(\mathrm{N}=2,350)$

\begin{tabular}{|c|c|c|c|c|}
\hline Variables & $\begin{array}{c}\text { IA } \\
\mathrm{N}=415\end{array}$ & $\begin{array}{c}\text { NA } \\
\mathrm{N}=1,935\end{array}$ & $\begin{array}{l}\text { test } \\
\text { value }\end{array}$ & $p$ value \\
\hline Age (Mean \pm SD) & $20.98 \pm 1.81$ & $20.91 \pm 1.91$ & 0.662 & 0.433 \\
\hline \multicolumn{5}{|l|}{ Gender } \\
\hline Male & $225(54.2)$ & $789(40.8)$ & \multirow{2}{*}{25.169} & \multirow{2}{*}{$<0.001$} \\
\hline Female & $190(45.8)$ & $1,146(59.2)$ & & \\
\hline \multicolumn{5}{|l|}{ Age group in years } \\
\hline$\leq 20$ & $175(42.2)$ & $849(43.9)$ & \multirow{2}{*}{0.759} & \multirow{2}{*}{0.358} \\
\hline$>20$ & $240(57.8)$ & $1,086(56.1)$ & & \\
\hline \multicolumn{5}{|l|}{ Family income } \\
\hline$<\$ 1.000$ & $19(4.6)$ & $427(22.1)$ & \multirow{4}{*}{93.436} & \multirow{4}{*}{$<0.001$} \\
\hline$\$ 1.000-1.999$ & $145(34.9)$ & $617(31.9)$ & & \\
\hline$\$ 2.000-2.999$ & $123(29.6)$ & $573(29.6)$ & & \\
\hline$>\$ 3.000$ & $128(30.8)$ & $318(16.4)$ & & \\
\hline \multicolumn{5}{|l|}{ Father education } \\
\hline Primary & $98(23.6)$ & $438(22.6)$ & \multirow{4}{*}{10.746} & \multirow{4}{*}{0.030} \\
\hline Intermediate & $92(22.2)$ & $363(18.8)$ & & \\
\hline Secondary & $122(29.4)$ & $515(26.6)$ & & \\
\hline University & $103(24.8)$ & $619(32.0)$ & & \\
\hline \multicolumn{5}{|l|}{ Father occupation } \\
\hline Not working & $40(9.6)$ & $211(10.9)$ & \multirow{5}{*}{81.898} & \multirow{5}{*}{$<0.001$} \\
\hline Sedentary/Professional & $118(28.4)$ & $496(25.6)$ & & \\
\hline Manual & $61(14.7)$ & $666(34.4)$ & & \\
\hline Businessman & $99(23.9)$ & $315(16.3)$ & & \\
\hline Government officer & $97(23.4)$ & $247(12.8)$ & & \\
\hline \multicolumn{5}{|l|}{ Rank in school exam } \\
\hline Very good & $110(26.5)$ & $411(21.2)$ & \multirow{4}{*}{36.613} & \multirow{4}{*}{$<0.001$} \\
\hline Good & $173(40.7)$ & $966(48.1)$ & & \\
\hline Average & $95(22.4)$ & $540(26.9)$ & & \\
\hline Poor & $43(10.1)$ & $80(4.0)$ & & \\
\hline \multicolumn{5}{|l|}{ Frequency of watching TV } \\
\hline Never & $18(4.3)$ & $122(6.3)$ & \multirow{4}{*}{47.481} & \multirow{4}{*}{$<0.001$} \\
\hline Rarely & $69(16.6)$ & $612(31.6)$ & & \\
\hline Sometimes & $119(28.7)$ & $629(32.5)$ & & \\
\hline Always & $209(50.4)$ & $572(29.6)$ & & \\
\hline \multicolumn{5}{|l|}{ Physical activity } \\
\hline Yes & $179(43.1)$ & $1,058(54.7)$ & \multirow{2}{*}{38.486} & \multirow{2}{*}{$<0.001$} \\
\hline No & $236(56.9)$ & $877(45.3)$ & & \\
\hline & Mean \pm SD & Mean \pm SD & & \\
\hline No of bedrooms at your home & $3.48 \pm 1.01$ & $3.62 \pm 1.09$ & -4.155 & 0.016 \\
\hline No of people are living at home & $5.60 \pm 2.08$ & $4.82 \pm 1.86$ & 7.403 & $<0.001$ \\
\hline Hours of internet use / day & $4.45 \pm 1.65$ & $3.86 \pm 1.73$ & -11.896 & $<0.001$ \\
\hline Sleeping duration / day & $6.06 \pm 1.10$ & $6.84 \pm 1.35$ & -12.575 & $<0.001$ \\
\hline TV watching in hours / day & $2.03 \pm 1.11$ & $1.82 \pm 1.25$ & -10.493 & $<0.001$ \\
\hline
\end{tabular}


Table 2. Confirmatory factor analysis of Internet Addiction Test (IAT) $(\mathrm{N}=\mathbf{2}, 350)$

\begin{tabular}{|c|c|c|c|c|c|}
\hline \multirow{2}{*}{ Items } & \multicolumn{4}{|c|}{ Factors } & \multirow[b]{2}{*}{ Communality } \\
\hline & 1 & 2 & 3 & 4 & \\
\hline q11. How often you go online again & 0.716 & & & & 0.631 \\
\hline $\begin{array}{l}\text { q20. How often feel depressed moody nervous } \\
\text { when offline }\end{array}$ & 0.683 & & & & 0.692 \\
\hline q17.Cut down the amount of online time & 0.651 & & & & 0.621 \\
\hline $\begin{array}{l}\text { q13. How often snap yell or act annoyed when } \\
\text { online }\end{array}$ & 0.647 & & & & 0.671 \\
\hline $\begin{array}{l}\text { q12. How often feel without internet would be } \\
\text { boring, empty and joyless }\end{array}$ & 0.638 & & & & 0.442 \\
\hline $\begin{array}{l}\text { q15.How often feel pre-occupied with the internet } \\
\text { when offline }\end{array}$ & 0.600 & & & & 0.665 \\
\hline $\begin{array}{l}\text { q19. How often spend more time online over going } \\
\text { out with others }\end{array}$ & 0.534 & & & & 0.683 \\
\hline q18. How often try to hide online time & 0.531 & & & & 0.642 \\
\hline $\begin{array}{l}\text { q10.How often do you block out concerning internet } \\
\text { user }\end{array}$ & 0.471 & & & & 0.542 \\
\hline q6. Your grades or school suffer from online & & 0.712 & & & 0.716 \\
\hline $\begin{array}{l}\text { q8.Job performance or productivity suffer from } \\
\text { online }\end{array}$ & & 0.703 & & & 0.652 \\
\hline $\begin{array}{l}\text { q9.Become defensive or secretive concerning } \\
\text { online }\end{array}$ & & 0.622 & & & 0.704 \\
\hline q7.How often checking your email & & 0.620 & & & 0.428 \\
\hline q3.Excitement of internet with your partner & & 0.538 & & & 0.612 \\
\hline $\begin{array}{l}\text { 95.Others complain about the amount of online } \\
\text { time }\end{array}$ & & 0.502 & & & 0.610 \\
\hline q4.New relationship online users & & 0.455 & & & 0.593 \\
\hline q16. How often saying a few minutes more & & & 0.718 & & 0.517 \\
\hline q14. How often lose sleep due to late login & & & 0.609 & & 0.421 \\
\hline q1.Stay online longer & & & & 0.745 & 0.554 \\
\hline q2.Spend more time online & & & & 0.672 & 0.704 \\
\hline Variance extracted & 18.76 & 13.65 & 12.18 & 10.56 & \\
\hline Construct Reliability & 0.86 & 0.79 & 0.57 & 0.48 & \\
\hline
\end{tabular}


Figure 1: Standardized Scores of Four-factor Structure of Internet Addiction Scale

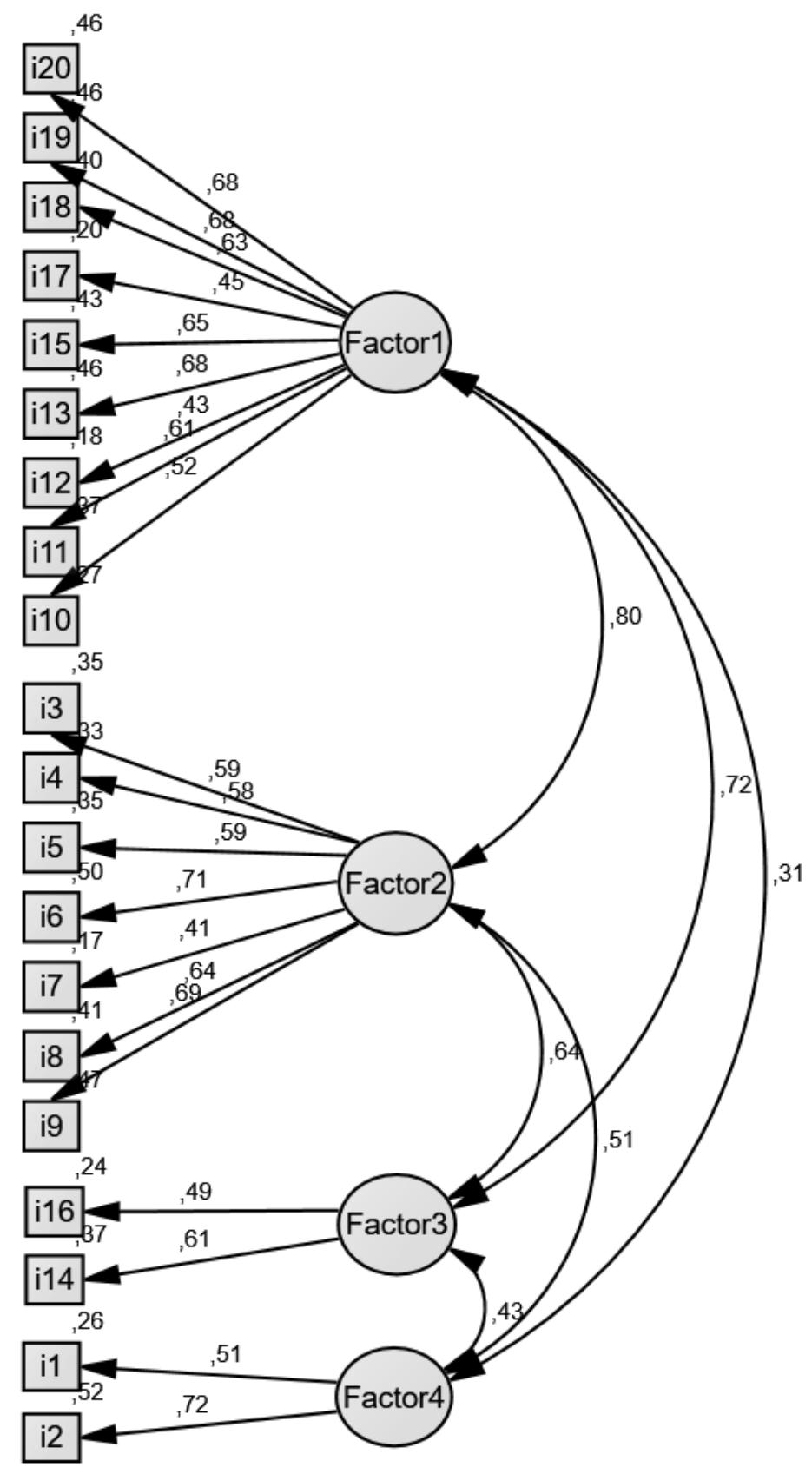


Table 3. The Characteristics of Lifestyle, Dietary and Co-morbid Factors between Internet Addicts and Normal Students $(\mathrm{N}=2,350)$

\begin{tabular}{|c|c|c|c|}
\hline Variables & $\underset{\mathrm{N}=415}{\mathrm{IA}}$ & $\begin{array}{l}\text { Normal } \\
\mathrm{N}=1,935\end{array}$ & p value * \\
\hline IAT Score (Mean \pm SD) & $71.28 \pm 5.70$ & $43.80 \pm 12.95$ & $<0.001$ \\
\hline Fatigue physical symptoms & $21.92 \pm 3.80$ & $19.73 \pm 4.47$ & $<0.001$ \\
\hline Fatigue mental symptoms & $15.29 \pm 3.34$ & $13.67 \pm 3.73$ & $<0.001$ \\
\hline Epworth Sleepiness Score & $6.23 \pm 4.21$ & $6.11 \pm 3.75$ & 0.570 \\
\hline Medical-Co-morbid Factors ${ }^{\star \star}$ & n (\%) & n (\%) & \\
\hline Headaches & $236(55.5)$ & $1,282(63.8)$ & 0.001 \\
\hline Blurred Vision & $113(26.5)$ & $759(37.7)$ & $<0.001$ \\
\hline Double Vision & $77(18.1)$ & $207(10.3)$ & $<0.001$ \\
\hline Eyes Hurt & 109(25.6) & $795(39.6)$ & $<0.001$ \\
\hline Eye Tire & $109(25.6)$ & $467(23.2)$ & 0.287 \\
\hline Dizziness & $164(38.5)$ & $754(37.5)$ & 0.678 \\
\hline $\begin{array}{l}\text { Any Problem with } \\
\text { Hearing }\end{array}$ & $130(30.5)$ & $343(17.0)$ & $<0.001$ \\
\hline The Epworth Sleepiness Scale & & & \\
\hline Normal & $361(84.9)$ & $1,733(86.2)$ & \multirow{4}{*}{0.123} \\
\hline Mild & $47(11.1)$ & $226(11.2)$ & \\
\hline Moderate & $11(2.6)$ & $42(2.1)$ & \\
\hline Severe & $6(1.4)$ & $9(0.4)$ & \\
\hline \multicolumn{4}{|l|}{ Activities } \\
\hline Vigorous activity & $179(42.1)$ & $1,058(52.6)$ & $<0.001$ \\
\hline Moderate activity & $210(49.4)$ & $1,301(64.7)$ & $<0.001$ \\
\hline \multicolumn{4}{|l|}{ Frequency of eating fast food* } \\
\hline Daily & $114(27.1)$ & $418(21.7)$ & \multirow{4}{*}{$<0.001$} \\
\hline Weekly & 142(33.8) & $779(40.4)$ & \\
\hline Monthly & $100(23.8)$ & $318(16.5)$ & \\
\hline Occasionally & $64(15.2)$ & 412(21.4) & \\
\hline
\end{tabular}

${ }^{*}$ Two sided $p$ values based on student $t$ test

${ }^{* *}$ Not adding to $100 \%$ 


\section{Table 4. The Comparison of Fatigue Physical and Mental Symptoms According Internet Addiction and Normal Subjects $(\mathrm{N}=2,350)$}

\begin{tabular}{|c|c|c|c|}
\hline 14 - Item fatigue scale & $\underset{N=415}{\mathrm{IA}}$ & $\begin{array}{l}\text { Normal Students } \\
\qquad N=1,935\end{array}$ & $\mathrm{p}$ value \\
\hline \multicolumn{4}{|l|}{ Physical symptoms } \\
\hline 1. Do you have problem with tiredness? & $2.80 \pm 1.20$ & $2.41 \pm 1.03$ & $<0.001$ \\
\hline 2. Do you need to rest more? & $2.73 \pm 1.24$ & $2.50 \pm 1.01$ & $<0.001$ \\
\hline 3. Do you feel sleepy or drowsy? & $2.71 \pm 2.08$ & $2.43 \pm 1.06$ & $<0.001$ \\
\hline 4 Do you have problems starting things? & $2.67 \pm 1.10$ & $2.50 \pm 1.12$ & 0.031 \\
\hline $\begin{array}{l}\text { 5. Do you start things without difficulty but } \\
\text { get weak as you go on? }\end{array}$ & $2.61 \pm 1.10$ & $2.49 \pm 1.06$ & $<0.001$ \\
\hline 6. Are you lacking in energy? & $2.93 \pm 1.11$ & $2.51 \pm 1.07$ & $<0.001$ \\
\hline $\begin{array}{l}\text { 7. Do you have less strength in your } \\
\text { muscle? }\end{array}$ & $2.67 \pm 1.09$ & $2.36 \pm 1.10$ & $<0.001$ \\
\hline 8. Do you feel weak? & $2.81 \pm 1.16$ & $2.52 \pm 1.12$ & $<0.001$ \\
\hline \multicolumn{4}{|l|}{ Mental symptoms } \\
\hline 9. Do you have difficulty concentrating? & $2.53 \pm 1.13$ & $2.41 \pm 0.99$ & 0.023 \\
\hline 10. Do you have problems thinking clearly & $2.74 \pm 1.08$ & $2.42 \pm 1.12$ & $<0.001$ \\
\hline $\begin{array}{l}\text { 11. Do you make lips of the tongue when } \\
\text { speaking? }\end{array}$ & $2.66 \pm 1.16$ & $2.39 \pm 1.10$ & $<0.001$ \\
\hline $\begin{array}{l}\text { 12. Do you find it more difficult to find the } \\
\text { correct word? }\end{array}$ & $2.55 \pm 1.27$ & $2.51 \pm 1.13$ & 0.558 \\
\hline 13. How is your memory? & $2.44 \pm 1.13$ & $2.53 \pm 1.00$ & 0.112 \\
\hline $\begin{array}{l}\text { 14. Have you lot interest in the things you } \\
\text { used to do? }\end{array}$ & $2.60 \pm 1.18$ & $2.48 \pm 1.04$ & 0.040 \\
\hline
\end{tabular}

\section{Table 5. Multiple Stepwise Regression Analysis Predictors for Determinants of Internet Addiction Affect ( $N=2,350)$}

\begin{tabular}{l|c|c|c|c|c}
\hline \hline Independent Variables & B & $\begin{array}{c}\text { Standard } \\
\text { Error }\end{array}$ & Beta & t test value & p-value \\
\hline & & & & & \\
\hline Internet use in hours & 0.048 & 0.114 & 0.008 & 0.422 & $<0.001$ \\
\hline Sleeping in hours & -3.127 & 0.221 & -0.264 & -14.177 & 0.041 \\
\hline Fatigue physical symptoms & 0.236 & 0.067 & 0.066 & 3.549 & $<0.001$ \\
\hline Fatigue mental symptoms & 0.652 & 0.081 & 0.152 & 8.001 & $<0.001$ \\
\hline Epworth Sleepiness Score & 0.407 & 0.074 & 0.098 & 5.534 & $<0.001$ \\
\hline Mental Disorders & -2.590 & 1.351 & -0.034 & -1.916 & 0.038 \\
\hline Headaches & 3.115 & 0.633 & 0.095 & 4.919 & $<0.001$ \\
\hline Blurred vision & 1.857 & 0.661 & 0.056 & 2.811 & 0.005 \\
\hline Double vision & -2.204 & 0.997 & -0.044 & -2.210 & 0.027 \\
\hline Eyes hurt & 5.338 & 0.651 & 0.162 & 8.195 & $<0.001$ \\
\hline Eye tired & -4.303 & 0.768 & -0.115 & -5.606 & $<0.001$ \\
\hline Dizziness & -1.949 & 0.656 & -0.059 & -2.973 & 0.003 \\
\hline Hearing problem & -4.306 & 0.735 & -0.107 & -5.860 & $<0.001$ \\
\hline
\end{tabular}

